\title{
Potencial alelopático da parte aérea de Senna occidentalis (L.) Link (Fabaceae, Caesalpinioideae): bioensaios em laboratório
}

\author{
Ana Carina da Silva Cândido¹, Valerí Schmidt ${ }^{1}$, Valdemir Antônio Laura², Odival Faccenda ${ }^{3}$, Sônia Corina Hess ${ }^{4}$, \\ Euclésio Simionatto ${ }^{4}$ e Marize Terezinha Lopes Pereira Peres ${ }^{4,5}$
}

Recebido em 3/10/2008. Aceito em 22/10/2009

RESUMO - (Potencial alelopático da parte aérea de Senna occidentalis (L.) Link (Fabaceae, Caesalpinioideae): Bioensaios em laboratório). A bioatividade das frações semipurificadas (hexânica, acetato de etila e etanol-água) do extrato etanólico das partes aérea de $S$. occidentalis foi avaliada através de ensaios de germinação e de crescimento de Lactuca sativa (alface), Lycopersicon esculentum (tomate), Allium cepa (cebola) e Triticum aestivum (trigo), em laboratório. Foram utilizadas três concentrações $\left(250,500,1000 \mathrm{mg} \mathrm{L}^{-1}\right)$ de cada fração e um controle não tratado, com quatro repetições de 50 sementes. Os bioensaios de germinação revelaram que todas as frações atrasaram a germinação de alface, tomate e cebola, e as frações hexânica e acetato de etila reduziram a germinabilidade de tomate e cebola. Nos bioensaios de crescimento, a fração hexânica estimulou o crescimento da raiz e inibiu o crescimento do hipocótilo das eudicotiledôneas. A mesma fração inibiu o crescimento da raiz e do coleóptilo das monocotiledôneas. A fração acetato de etila inibiu o crescimento da raiz das plântulas-alvo e o hipocótilo/coleóptilo de tomate e cebola. A fração etanol-água estimulou o crescimento da raiz de tomate e do hipocótilo de alface e inibiu o crescimento da raiz de cebola e trigo e, também, do coleóptilo de cebola, na concentração de $1000 \mathrm{mg} \mathrm{L}^{-1}$. Nos bioensaios com herbicidas comerciais foram observados efeitos semelhantes àqueles obtidos na germinação pelas frações e no crescimento pelas frações hexânica e acetato de etila. Na cromatografia em camada delgada, foram detectados terpenos na fração hexânica, compostos fenólicos e alcalóides na fração acetato de etila. A análise espectrofotométrica revelou que a fração acetato de etila possui o maior conteúdo de compostos fenólicos e flavonóides.

Palavras-chave: aleloquímicos, herbicidas naturais, plantas daninhas

\begin{abstract}
Allelopathic potential of aerial parts of Senna occidentalis (L.) Link (Fabaceae, Caesalpinioideae): Laboratory bioassays). The bioactivity of semipurified fractions (hexane, ethyl acetate and ethanol-water) obtained from $S$. occidentalis aerial-part ethanol extract was evaluated by germination and growth bioassays using Lactuca sativa (lettuce), Lycopersicon esculentum (tomato), Allium cepa (onion) and Triticum aestivum (wheat), in the laboratory. Three concentrations of each fraction $\left(250,500,1000 \mathrm{mg} \mathrm{L}^{-1}\right)$ and untreated control were used, on four replicates of 50 seeds each. Germination bioassays revealed that lettuce, tomato and onion germination were delayed by all tested semipurified fractions, and tomato and onion germination were inhibited by the hexane and ethyl acetate fractions. In growth bioassays, the hexane fraction stimulated root growth and inhibited hypocotyl growth in the eudicots. The same fraction inhibited root and coleoptile growth of the assayed monocots. The ethyl acetate fraction inhibited seedling roots and hypocotyl/coleoptile growth, of tomato and onion. The ethanol-water fraction stimulated tomato root growth and lettuce hypocotyl growth, and inhibited onion and wheat root and onion coleoptile development at 1000 $\mathrm{mg} \mathrm{L}^{-1}$. Bioassays performed with commercial herbicides presented similar results to those observed in germination to the semipurified fractions in the growth by hexane and ethyl acetate fractions. The layer chromatography revealed that the tested hexane fraction contains terpenes, and the ethyl acetate fraction has phenolic compounds and alkaloids. The spectrophotometric analysis revealed greater yields of phenolic compounds and flavonoids in the ethyl acetate fraction.

Key words: allelochemicals, natural herbicides, weeds
\end{abstract}

\section{Introdução}

As plantas superiores e inferiores produzem substâncias químicas que são produtos do metabolismo secundário e fazem parte do seu sistema de defesa. Muitos desses compostos químicos estão relacionados com as interações planta-planta e são denominados de aleloquímicos (Macias et al. 2000a).

Os aleloquímicos são liberados pelas plantas através de exsudação radicular, lixiviação, volatilização ou decomposição, influenciando de forma favorável ou desfavorável o crescimento e desenvolvimento de sistemas biológicos e agrícolas (Rice 1984; Macias et al. 2000a). Os compostos alelopáticos pertencem a diferentes classes de compostos químicos, tais como fenóis, terpenos, alcalóides, poliacetilenos, ácidos graxos, peptídeos, entre outros (Einhellig 2002). Em termos de aplicação prática e comercial, um dos alvos mais importante dos estudos alelopáticos é a descoberta de herbicidas naturais, que são ambientalmente e toxicologicamente mais seguros que os herbicidas sintéticos usados atualmente na agricultura (Macias et al. 2000b; Duke et al. 2002).
Senna occidentalis (L.) Link (Fabaceae, Caesalpinioideae), conhecida popularmente como "fedegoso", é uma planta invasora encontrada em todo o território brasileiro (Rodrigues et al. 2005), sendo muito freqüente no Estado de Mato Grosso do Sul em pastagens, pomares, terrenos baldios e solos cultivados, especialmente com a soja (Lorenzi 2000). As espécies de Senna são bem conhecidas na medicina popular como laxativas, purgativas (Viegas Junior et al. 2006) e antioxidantes (Luximon-Ramma et al. 2002). Estudos químicos com o gênero levaram ao isolamento de antraquinonas (Kim et al. 2004), flavonóides (Luximon-Ramma et al. 2002; Viegas Junior et al. 2006), compostos fenólicos e proantocianidinas (Luximon-Ramma et al. 2002). Estudos biológicos com $S$. occidentalis comprovaram propriedades purgativa, hepática, bactericida, antipirética, antitumoral, expectorante, antiinflamatória, diurética, antifúngica e neurotóxica para bovinos (Viegas Junior et al. 2006), e estudos químicos levaram ao isolamento de antraquinonas, flavonóides, polissacarideos (Chauhan et al. 2001), alcalóides piperidínicos (Viegas Junior et al. 2006) e xantonas (Wader \& Kudak 1987).

\footnotetext{
1 Universidade Federal de Mato Grosso do Sul, Programa de Pós-Graduação em Biologia Vegetal, Campo Grande, MS, Brasil

2 Embrapa Gado de Corte, Campo Grande, MS, Brasil

3 Universidade Estadual de Mato Grosso do Sul, Departamento de Ciências da Computação, Campus de Dourados, Dourados, MS, Brasil

4 Universidade Federal de Mato Grosso do Sul, Departamento de Hidráulica e Transporte, Campo Grande, MS, Brasil

5 Autor para correspondência: mperes@propp.ufms.br
} 
Em condições de campo, é observado que $S$. occidentalis forma grupamentos quase que puros e dificulta o estabelecimento de outras espécies, sugerindo efeito alelopático. Peres et al. (comunicação pessoal) verificaram que o extrato etanólico bruto das partes aérea e subterrânea dessa planta retardou a germinação e inibiu o crescimento de alface e cebola. O levantamento bibliográfico indicou ausência de informações a respeito da atividade alelopática de $S$. occidentalis, justificando a realização destes estudos.

O presente trabalho foi realizado com o objetivo de avaliar o potencial de atividade alelopática das frações semipurificadas (hexânica, acetato de etila e etanol-água) obtidas do extrato etanólico da parte aérea de $S$. occidentalis, através de bioensaios de germinação e crescimento em laboratório com as eudicotiledôneas alface e tomate e com as monocotiledôneas cebola e trigo.

\section{Material e métodos}

Preparo do extrato etanólico bruto e frações semipurificadas - Senna occidentalis (L.) Link foi coletada num fragmento de cerrado na Fazenda Boa Vista, município de Rio Brilhante (MS, Brasil) nas coordenadas geográficas $21^{\circ} 45^{\prime} \mathrm{S}$ e $54^{\circ} 32^{\prime} \mathrm{W}$, em novembro de 2002 . Uma exsicata da espécie foi incorporada ao acervo do Herbário DDMS da Universidade Federal da Grande Dourados (UFGD) em Dourados (MS), sob o seguinte número: BRASIL. MS: Rio Brilhante, Faz. Boa Vista, Sciamarelli, A. 212 (DDMS). Após coleta, as partes aérea (folhas, flores e frutos) e subterrânea foram separadas e reduzidas a pequenos fragmentos. A matéria fresca teve sua massa registrada e foi acondicionada em saco plástico a $-7^{\circ} \mathrm{C}$. Posteriormente, a parte aérea de $S$. occidentalis foi submetida à extração através de maceração com etanol absoluto $(\mathrm{m} / \mathrm{v}, 1: 2)$, à temperatura ambiente. Após 7 dias, foi feita filtragem e o material sólido descartado, sendo o solvente evaporado $\left( \pm 40^{\circ} \mathrm{C}\right)$ sob vácuo em evaporador rotativo para obtenção do extrato etanólico bruto (EEB). Para obtenção das frações semipurificadas, o EEB foi fracionado através de partição líquido-líquido com solventes de diferentes graus de polaridade, hexano e acetato de etila, em funil de decantação, sendo obtidas as frações hexânica (FH), acetato de etila (FAE) e etanol-água (FEA). O teor de água foi determinado a partir de uma alíquota das frações, submetida à secagem $\left(100^{\circ} \mathrm{C}\right)$ por $10 \mathrm{~h}$, até obtenção de massa constante.

Bioensaios de germinação e crescimento - Para preparo da solução estoque (1000 $\mathrm{mg} \mathrm{L}^{-1}$ ) das frações (FH, FAE e FEA), foi considerado seu teor de água e utilizado dimetilsufóxido (DMSO) 0,1\% (Dayan et al. 2000), sendo removida a porção não solúvel. Soluções diluídas $\left(500\right.$ e $\left.250 \mathrm{mg} \mathrm{L}^{-1}\right)$ foram preparadas a partir da solução estoque, tamponada com ácido 2-morfolinoetanosulfônico (MES) $10 \mathrm{mM}$ e o pH ajustado para 6,0 com KOH 0,1 N (Macias et al. 2000a). As frações foram ensaiadas com as eudicotiledôneas alface (Lactuca sativa L. cv. Grand rapids) e tomate (Lycopersicon esculentum Mill cv. Santa Clara) e com as monocotiledôneas cebola (Allium cepa L. cv. Baia Periforme) e trigo (Triticum aestivum L. cv. RRS 220).

No bioensaio de germinação, foi aplicada a metodologia de Macias et al. (2000a). Placas de Petri ( $9,0 \mathrm{~cm}$ de diâmetro) contendo papel filtro Whatman $\mathrm{n}^{\circ} .1$, ambos previamente autoclavados a $120^{\circ} \mathrm{C}$ por 20 minutos, receberam $5 \mathrm{~mL}$ das frações nas concentrações de 250,500 e 1000 $\mathrm{mg} \mathrm{L}^{-1}$. Em seguida, foram semeados sobre cada disco de papel filtro 50 diásporos das espécies alvo (alface, tomate, cebola e trigo), distribuídos aleatoriamente, com 4 repetições para cada solução, conforme Brasil (1992). Como controle, procedimento similar foi utilizado, porém com ausência das frações. As sementes de trigo foram tratadas com o fungicida Benlate 500 PM 1,0 $\mathrm{g} \mathrm{L}^{-1}$ (Araújo \& Araújo 2006). As placas de Petri contendo os diásporos foram levadas a uma câmara de germinação (BOD), com condições de luz $\left(160 \mathrm{~W} \mathrm{~m}^{-2}\right)$, umidade relativa $( \pm 80 \%)$ e temperatura constante, adequada a cada espécie alvo (alface, $25^{\circ} \mathrm{C}$ com luz interna constante; tomate, $25^{\circ} \mathrm{C}$ e fotoperíodo de $12 \mathrm{~h}$; cebola, $15^{\circ} \mathrm{C}$ e fotoperíodo de $12 \mathrm{~h}$; e trigo $15^{\circ} \mathrm{C}$, no escuro) (Brasil 1992). A contagem para avaliar a germinação foi realizada diariamente (sendo que para alface a cada $12 \mathrm{~h}$ ), tendo como critério a protrusão radicular com no mínimo $2 \mathrm{~mm}$ de comprimento. $\mathrm{O}$ experimento foi considerado concluído quando não ocorreu germinação por três dias consecutivos. No bioensaio de crescimento foi utilizada a metodologia descrita por Barnes et al. (1987) e Macias et al. (2000a). Após três dias da protrusão radicular, foi medido o alongamento da raiz e do hipocótilo/coleóptilo (dez plântulas por placa), utilizando papel milimetrado. Posteriormente, essas plântulas foram levadas a estufa a 60 ${ }^{\circ} \mathrm{C}$ até peso constante, para obtenção da massa seca.

Bioensaios de germinação e crescimento foram realizados também com herbicidas comerciais (Macias et al. 2000a). Foram utilizados para as eudicotiledôneas glifosato 480 (pós-emergente), basagran 600 (pós-emergente) e atrazina $500 \mathrm{SC}$ (misto) e para as monocotiledôneas glifosato 480 (pós-emergente), gesagard 500 SC (Pré-emergente) e poast (pós-emergente). Todos os herbicidas foram aplicados $(5 \mathrm{~mL})$ em concentrações equivalentes de composto ativo $\left(10^{-2}, 10^{-3} \mathrm{e} 10^{-4} \mathrm{M}\right.$ ) (Macias et al. 2000a). Para os bioensaios com herbicidas, procedimentos similares aos descritos com as frações foram empregados. Nos bioensaios, foi adotado o delineamento experimental inteiramente casualizado, envolvendo três ensaios simples, com FH, FAE e FEA da parte aérea de $S$. occidentalis $\left(0,250,500\right.$ e $\left.1000 \mathrm{mg} \mathrm{L}^{-1}\right)$ ou com herbicidas $\left(0,10^{-2}, 10^{-3} \mathrm{e} 10^{-4} \mathrm{M}\right)$, em quatro repetições. Cada parcela foi constituída de 50 diásporos para germinação e 10 diásporos para crescimento da raiz e do hipocótilo/coleóptilo. A porcentagem de germinação $(\% \mathrm{G})$ foi calculada segundo metodologia descrita por Labouriau (1983) e o índice de velocidade de germinação (IVG) de acordo com Maguire (1962), citado por Ferreira \& Borghetti (2004). Os dados foram submetidos à análise de variância e quando os efeitos dos tratamentos foram significativos ( $\mathrm{p}<0,05)$, as médias foram comparadas pelo teste de Dunnet. Quando uma das pressuposições exigidas pelo modelo paramétrico não foi atendida, foram utilizados testes estatísticos não paramétricos, Kruskal-Wallis como alternativa para a análise de variância e Mann-Whitney como alternativa para o teste de Dunnet. Os resultados foram analisados considerando o nível de significância $\alpha=5 \%$.

Análise química das frações semipurificadas - Foram realizados testes preliminares de cromatografia em camada delgada (CCD) em placas de sílica-gel (Merk), a fim de detectar a presença de algumas classes de compostos nas frações semipurificadas. Nesses testes, foram utilizados como reagentes indicadores soluções de vanilina/etanol- $\mathrm{H}_{2} \mathrm{SO}_{4} 1 \%$ e cloreto férrico $1 \%$, substâncias estas que são reativas na presença de terpenos e compostos fenólicos, respectivamente.

Para detecção de alcalóides, $5 \mathrm{~g}$ do extrato etanólico foram dissolvidos em $10 \mathrm{~mL}$ de água destilada, seguida de acidificação com $\mathrm{HCl} 2 \mathrm{~N}$ para $\mathrm{pH}$ 1,5. Feito isso, foram realizadas várias extrações com éter etílico, através de fracionamento por partição líquido-líquido. A solução aquosa remanescente foi alcalinizada com hidróxido de amônio $\left(\mathrm{NH}_{4} \mathrm{OH}\right)$ para pH 9,0 e extraída com éter etílico e acetato de etila. Após eliminação dos solventes em evaporador rotativo, foram obtidas as respectivas frações básicas: etérea e acetato de etila. As frações foram analisadas em CCD e reveladas com uso do reativo Dragendorff (Morel et al. 2005).

O teor de fenóis totais das frações foi determinado pelo método FolinCiocalteu (Meda et al. 2005; Lin \& Tang 2007). Ácido gálico foi utilizado como substância referência, sendo usados 25 a $600 \mu \mathrm{g}$ para construção da curva padrão. Na determinação do teor de fenóis, $5 \mathrm{mg}$ de cada fração foram dissolvidos em $5 \mathrm{~mL}$ de água destilada. Alíquotas de $1 \mathrm{~mL}$ dessa solução foram transferidas para balões de $50 \mathrm{~mL}$, sendo acrescentados 30 $\mathrm{mL}$ de água destilada, $2 \mathrm{~mL}$ do reagente Folin Ciocalteau e, após 6 minutos, $6 \mathrm{~mL}$ de uma solução de carbonato de sódio $\left(\mathrm{Na}_{2} \mathrm{CO}_{3}\right) 20 \%$ e o volume final completado com água destilada. O branco do sistema foi preparado da mesma forma, contendo todos os reagentes exceto as frações. As soluções foram deixadas em repouso à temperatura ambiente e, precisamente após $1 \mathrm{~h}$ e 30 minutos, foram feitas leituras das absorbâncias a $760 \mathrm{~nm}$.

Para quantificação do teor de flavonóides, uma curva com quercetina $(5 \mathrm{a} 300 \mu \mathrm{g})$ foi construída. Frações semipurificadas $(8 \mathrm{mg})$ foram dissolvidas em $4 \mathrm{~mL}$ de etanol. Alíquotas de $2 \mathrm{~mL}$ dessa solução foram transferidas para balões de $25 \mathrm{~mL}$, sendo acrescentados $1 \mathrm{~mL}$ de cloreto de alumínio $2,5 \%, 1 \mathrm{~mL}$ de acetato de sódio $10 \%$ e completado o volume com etanol. Como branco, foi preparada uma solução contendo todos os reagentes, exceto as frações. Decorridos 40 minutos, foi feita a leitura a $425 \mathrm{~nm}$ (Lin \& Tang 2007). 


\section{Resultados e discussão}

Bioensaios de germinação e crescimento com eudicotiledôneas - Em relação ao processo germinativo das eudicotiledôneas, as frações avaliadas reduziram significativamente $(p<0,05)$ o índice de velocidade de germinação (IVG) de alface e tomate, pelo menos em uma das concentrações ensaiadas (Tab. 1). Porém, apesar de ter atrasado a germinação, efeitos não foram observados sobre a porcentagem de germinação de alface (Tab. 2). Em tomate, FH e FAE reduziram significativamente $(\mathrm{p}<0,05)$ a porcentagem de germinação na maior concentração avaliada (Tab. 2).

No crescimento das plântulas (Fig 1 e 2), a FH estimulou o crescimento da raiz de alface e tomate $(\mathrm{p}<0,05)$ em todas as concentrações ensaiadas. A FAE inibiu o crescimento da raiz de alface e tomate nas duas maiores concentrações. A FEA estimulou o crescimento da raiz de tomate nas concentrações mais elevadas, tendo sido verificado que o aumento da concentração resultou em maior estímulo. Em relação ao crescimento do hipocótilo (Fig. 1 e 2), alface e tomate foram inibidos significativamente $(\mathrm{p}<0,05)$ pela $\mathrm{FH}$ na maior concentração. A FAE inibiu significativamente $(\mathrm{p}<$ $0,05)$ o crescimento do hipocótilo de tomate, enquanto que a FEA estimulou o crescimento do hipocótilo de alface na concentração de $1000 \mathrm{mg} \mathrm{L}^{-1}$. Macias et al. (2006) observaram efeitos semelhantes a FH com lactonas sequisterpênicas isoladas de Helianthus annuus L., que estimularam o crescimento da raiz e inibiram o hipocótilo de alface. Em adição, Maraschin-Silva \& Áquila (2006) observaram que extratos aquosos da folha de Peltophorum dubium (Spreng.) Taub. (Fabaceae) inibiram o crescimento da raiz de alface, porém não causaram efeito no hipocótilo, corroborando com os resultados da FAE em alface. Efeitos similares a FH também foi verificado nos bioensaios com o herbicida atrazina, que estimulou o crescimento da raiz de alface em $51 \%$ e $53 \%$ nas concentrações de $10^{-3} \mathrm{M}$ e $10^{-2} \mathrm{M}$, respectivamente, e inibiu o crescimento do hipocótilo em $31 \%$ e 39\% nas concentrações $10^{-3} \mathrm{M}$ e $10^{-2} \mathrm{M}$, respectivamente. A FAE agiu de maneira semelhante ao herbicida glifosato $10^{-3} \mathrm{M}$, que inibiu o crescimento da raiz de alface em $48 \%$, não tendo afetado significativamente o crescimento do hipocótilo. Com esses resultados pode ser sugerido que FH e FAE possuem compostos químicos passíveis de estarem atuando em processos fisiológicos na plântula de maneira similar aos herbicidas citados, visto que os efeitos no crescimento foram similares.

Durante a condução dos experimentos, foi observado que nos casos de estímulo no crescimento das raízes, estas se apresentavam mais finas, enquanto que na inibição havia um espessamento, além de ausência de pêlos absorventes. Soares et al. (2002) observaram que extratos aquosos de espécies de leguminosas mostram forte efeito inibidor do desenvolvimento radicial de plântulas de alface, sendo esse resultado acompanhado de alterações morfológicas nas raízes como espessamento, fato também observado para a FAE, em nossos estudos.

Bioensaios de germinação e crescimento com monocotiledôneas - Por meio da análise dos dados de germinação, foi constatado que a FH, em todas as concentrações testadas, e FAE, 500 e $1000 \mathrm{mg} \mathrm{L}^{-1}$, reduziram significativamente $(\mathrm{p}<$ 0,05) o IVG (Tab. 1) e a porcentagem de germinação (Tab. 2) de cebola. Em trigo, nenhuma das frações afetou o processo germinativo (Tab. 1 e 2).

Tabela 1. Efeito das frações semipurificadas da parte aérea de Senna occidentalis no índice de velocidade de germinação (IVG) de alface, tomate, cebola e tri

\begin{tabular}{|c|c|c|c|c|}
\hline \multicolumn{5}{|c|}{ Índice de velocidade de germinação (IVG)* } \\
\hline & Controle & $250 \mathrm{mg} \mathrm{L}^{-1}$ & $500 \mathrm{mg} \mathrm{L}^{-1}$ & $1.000 \mathrm{mg} \mathrm{L}^{-1}$ \\
\hline \multicolumn{5}{|l|}{ ALFACE } \\
\hline Fração hexânica & $33,13 \pm 1,67 \mathrm{a}$ & $30,33 \pm 1,97 a$ & $24,50 \pm 1,46 b$ & $23,90 \pm 1,07 b$ \\
\hline Fração acetato de etila & $33,13 \pm 1,67 \mathrm{a}$ & $30,38 \pm 0,48 b$ & $23,96 \pm 0,82 b$ & $23,83 \pm 0,71 b$ \\
\hline Fração etanol-água & $33,13 \pm 1,67 \mathrm{a}$ & $33,43 \pm 2,70 \mathrm{a}$ & $30,18 \pm 2,55 \mathrm{a}$ & $28,06 \pm 0,99 b$ \\
\hline \multicolumn{5}{|l|}{ TOMATE } \\
\hline Fração hexânica & $13,60 \pm 0,26 \mathrm{a}$ & $11,68 \pm 0,78 b$ & $10,93 \pm 0,32 b$ & $9,95 \pm 1,11 b$ \\
\hline Fração acetato de etila & $13,60 \pm 0,26 \mathrm{a}$ & $12,70 \pm 0,44 \mathrm{a}$ & $9,97 \pm 1,23 b$ & $9,64 \pm 1,05 b$ \\
\hline Fração etanol-água & $13,60 \pm 0,26 \mathrm{a}$ & $12,34 \pm 1,06 \mathrm{a}$ & $11,97 \pm 1,15 \mathrm{a}$ & $11,38 \pm 1,24 b$ \\
\hline \multicolumn{5}{|l|}{ CEBOLA } \\
\hline Fração hexânica & $8,18 \pm 0,78 \mathrm{a}$ & $6,09 \pm 0,75 b$ & $5,51 \pm 0,83 b$ & $5,40 \pm 0,46 b$ \\
\hline Fração acetato de etila & $8,18 \pm 0,78 \mathrm{a}$ & $8,20 \pm 1,41 \mathrm{a}$ & $7,90 \pm 0,28 \mathrm{a}$ & $6,51 \pm 0,58 \mathrm{~b}$ \\
\hline Fração etanol-água & $8,18 \pm 0,78 \mathrm{a}$ & $9,46 \pm 1,21 \mathrm{a}$ & $8,97 \pm 0,64 a$ & $8,41 \pm 1,03 a$ \\
\hline \multicolumn{5}{|l|}{ TRIGO } \\
\hline Fração hexânica & $11,30 \pm 1,46 \mathrm{a}$ & $10,80 \pm 1,93 \mathrm{a}$ & $10,40 \pm 0,49 a$ & $10,30 \pm 1,14 a$ \\
\hline Fração acetato de etila & $11,30 \pm 1,46 a$ & $11,00 \pm 1,22 \mathrm{a}$ & $10,60 \pm 0,71 \mathrm{a}$ & $10,00 \pm 1,40 \mathrm{a}$ \\
\hline Fração etanol-água & $11,30 \pm 1,46 a$ & $12,60 \pm 1,66 \mathrm{a}$ & $12,20 \pm 1,22 \mathrm{a}$ & $11,00 \pm 0,87 \mathrm{a}$ \\
\hline
\end{tabular}

*Média \pm desvio padrão. Médias seguidas de mesma letra do controle não diferem entre si pelo teste de Dunnet a $5 \%$ de probabilidade. 
Tabela 2. Efeito das frações semipurificadas da parte aérea de Senna occidentalis na germinabilidade de alface, tomate, cebola e trigo.

\begin{tabular}{|c|c|c|c|c|}
\hline \multicolumn{5}{|c|}{ Germinabilidade $(\%)^{*}$} \\
\hline & Controle & $250 \mathrm{mg} \mathrm{L}^{-1}$ & $500 \mathrm{mg} \mathrm{L}^{-1}$ & $1.000 \mathrm{mg} \mathrm{L}^{-1}$ \\
\hline \multicolumn{5}{|l|}{ ALFACE } \\
\hline Fração hexânica & $100,00 \pm 0,00 \mathrm{a}$ & $97,00 \pm 2,00 \mathrm{a}$ & $96,00 \pm 2,83 a$ & $97,50 \pm 2,52 \mathrm{a}$ \\
\hline Fração acetato de etila & $100,00 \pm 0,00 \mathrm{a}$ & $97,50 \pm 1,91 \mathrm{a}$ & $98,50 \pm 1,00 \mathrm{a}$ & $98,00 \pm 2,83 a$ \\
\hline Fração etanol-água & $100,00 \pm 0,00 \mathrm{a}$ & $98,00 \pm 2,83 \mathrm{a}$ & $99,00 \pm 1,15 \mathrm{a}$ & $94,50 \pm 1,91 \mathrm{a}$ \\
\hline \multicolumn{5}{|l|}{ TOMATE } \\
\hline Fração hexânica & $91,50 \pm 3,00 \mathrm{a}$ & $93,50 \pm 3,00 \mathrm{a}$ & $89,00 \pm 2,58 \mathrm{a}$ & $85,00 \pm 2,58 b$ \\
\hline Fração acetato de etila & $91,50 \pm 3,00 \mathrm{a}$ & $94,50 \pm 2,52 \mathrm{a}$ & $87,50 \pm 3,00 \mathrm{a}$ & $84,50 \pm 3,00 b$ \\
\hline Fração etanol-água & $91,50 \pm 3,00 \mathrm{a}$ & $86,50 \pm 2,52 \mathrm{a}$ & $85,50 \pm 2,52 \mathrm{a}$ & $87,00 \pm 3,56 a$ \\
\hline \multicolumn{5}{|l|}{ CEBOLA } \\
\hline Fração hexânica & $86,00 \pm 2,82 \mathrm{a}$ & $77,00 \pm 3,83 b$ & $74,00 \pm 3,65 b$ & $72,00 \pm 2,82 b$ \\
\hline Fração acetato de etila & $86,00 \pm 2,82 \mathrm{a}$ & $87,00 \pm 2,58 \mathrm{a}$ & $78,50 \pm 2,51 b$ & $62,50 \pm 3,00 b$ \\
\hline Fração etanol-água & $86,00 \pm 2,82 \mathrm{a}$ & $91,50 \pm 3,41 \mathrm{a}$ & $87,00 \pm 2,58 \mathrm{a}$ & $86,50 \pm 3,00 \mathrm{a}$ \\
\hline \multicolumn{5}{|l|}{ TRIGO } \\
\hline Fração hexânica & $72,00 \pm 2,83 a$ & $70,50 \pm 2,52 \mathrm{a}$ & $72,50 \pm 1,91 \mathrm{a}$ & $72,50 \pm 2,52 \mathrm{a}$ \\
\hline Fração acetato de etila & $72,00 \pm 2,83 a$ & $67,50 \pm 3,42 \mathrm{a}$ & $72,50 \pm 2,52 \mathrm{a}$ & $68,00 \pm 2,31 \mathrm{a}$ \\
\hline Fração etanol-água & $72,00 \pm 2,83 a$ & $75,00 \pm 2,58 \mathrm{a}$ & $71,50 \pm 2,52 \mathrm{a}$ & $72,00 \pm 2,83 a$ \\
\hline
\end{tabular}

*Média \pm desvio padrão. Médias seguidas de mesma letra do controle não diferem entre si pelo teste de Dunnet a 5\% de probabilidade.
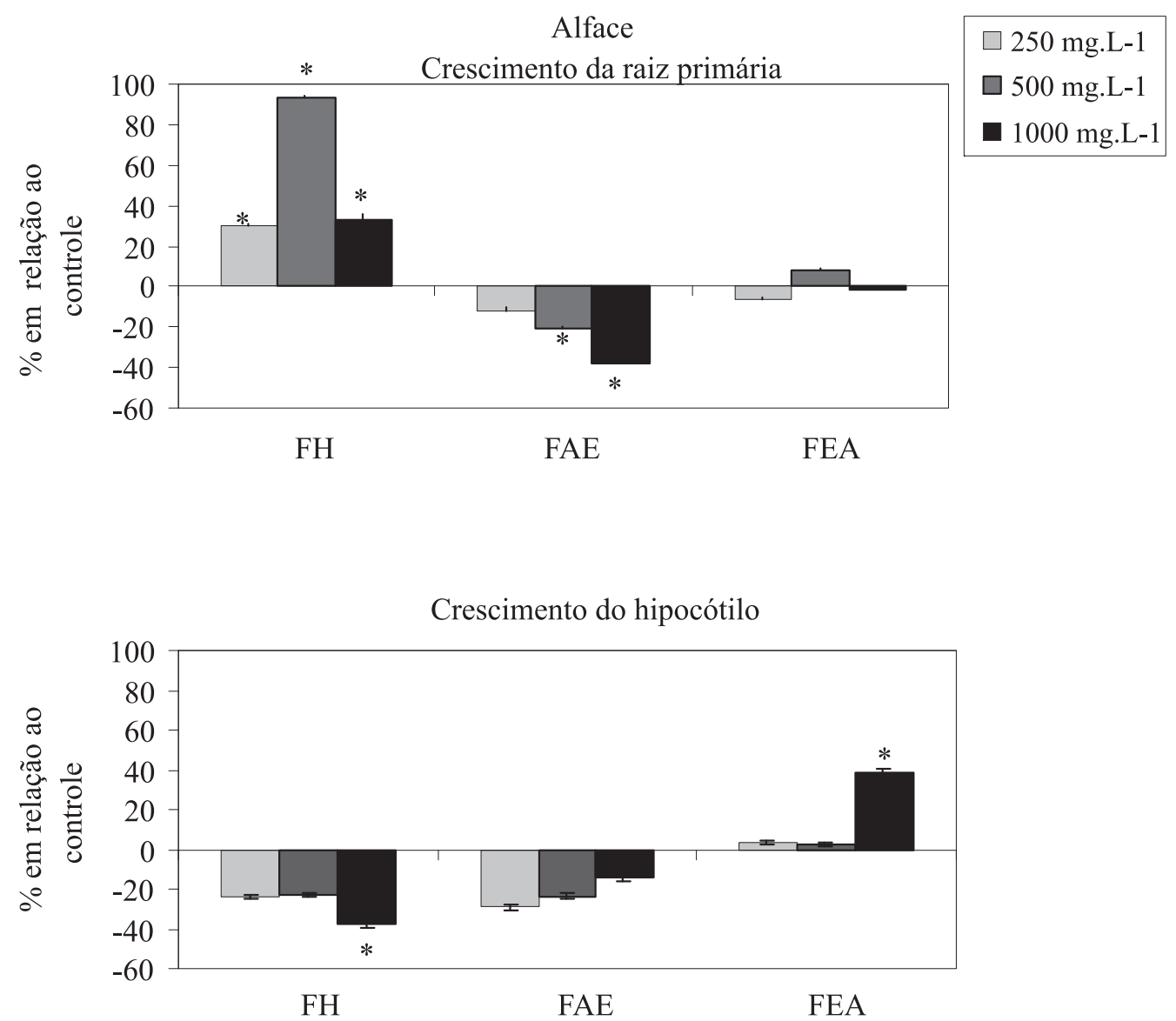

Figura 1. Efeito das frações hexânica (FH), acetato de etila (FAE) e etanol-água (FEA) da parte aérea de Senna occidentalis no crescimento médio da raiz e do hipocótilo de alface. Dados expressos em percentual em relação ao controle. *A média do tratamento difere significativamente ( $\mathrm{p}<0,05)$ em comparação com a média do controle, pelo teste de Dunnet. 

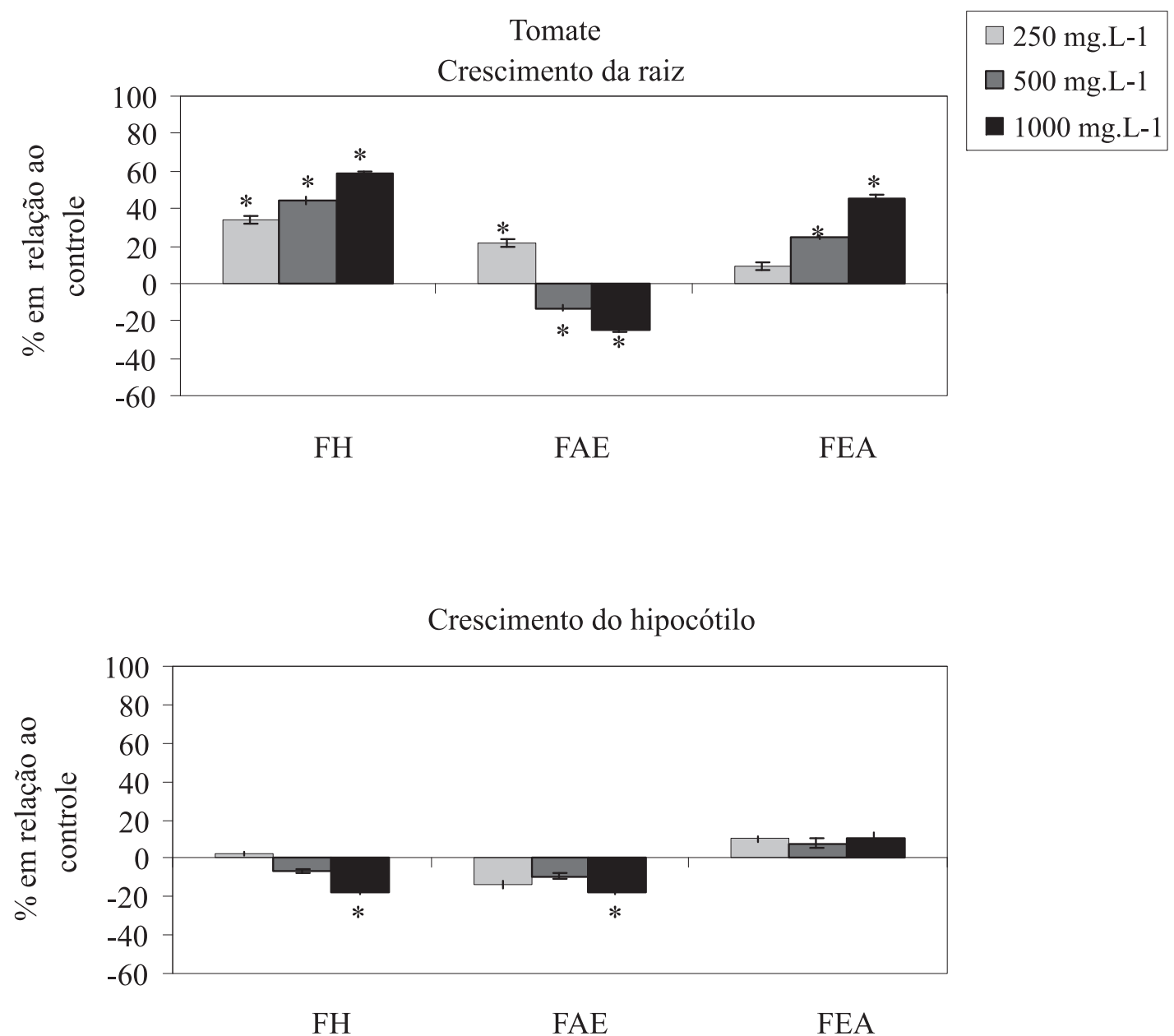

Figura 2. Efeito das frações hexânica (FH), acetato de etila (FAE) e etanol-água (FEA) da parte aérea de Senna occidentalis no crescimento médio da raiz e do hipocótilo de tomate. Dados expressos em percentual em relação ao controle. *A média do tratamento difere significativamente $(\mathrm{p}<0,05)$ em comparação com a média do controle, pelo teste de Dunnet.

Em relação ao crescimento radicial (Fig. 3 e 4), todas as frações inibiram significativamente $(\mathrm{p}<0,05)$ o desenvolvimento da raiz das monocotiledôneas analisadas, particularmente quando considerada a concentração de $1000 \mathrm{mg}$ $\mathrm{L}^{-1}$. Similarmente ao verificado com a raiz, o coleóptilo de cebola foi inibido significativamente $(\mathrm{p}<0,05)$ pelas frações quando esta foi submetida aos diferentes tratamentos (Fig. $3)$. Em trigo, apenas a FH afetou significativamente ( $p<$ $0,05)$ o crescimento do coleóptilo nas três concentrações analisadas (Fig. 4).

Nos resultados com monocotiledôneas, a cebola se mostrou mais sensível às frações do que o trigo, tanto na germinação quanto no crescimento, porém nos testes com os herbicidas essa sensibilidade não foi verificada. No crescimento de trigo, a maior concentração ensaiada de FAE agiu de maneira similar ao herbicida gesagard na menor concentração $\left(10^{-4} \mathrm{M}\right)$, que reduziu em $18 \%$ o crescimento da raiz, mas não afetou o crescimento do coleóptilo. Peres et al. (comunicação pessoal) verificaram que o EEB da parte aérea de $S$. occidentalis retardou a germinação de alface e cebola, corroborando com os resultados obtidos com as frações. Em estudos com samambaias, Peres et al. (2004) verificaram que extratos etanólicos de Adiantum serratodentatum Humb. \& Bonpl. ex Willd. e Pteris denticulata Sw. var. denticulata inibiram significativamente o crescimento de cebola.

De acordo com os resultados obtidos, para a germinação das espécies-alvo em estudo, pode ser concluído que FH e FAE possuem compostos químicos que afetam algum processo fisiológico durante a germinação de tomate e cebola, sendo a maior inibição com a cebola $(27,32 \%)$. Nessas frações, também foram detectados os maiores conteúdos totais de fenóis e flavonóides, além da presença de alcalóides na FAE (verificada pela CCD e reagente específico), classes químicas já reportadas na literatura com atividades alelopáticas (Duringan \& Almeida 1993; Einhellig 2002).

Nos bioensaios com herbicidas, foi verificado que nas eudicotiledôneas o herbicida glifosato agiu de maneira similar às frações em alface, reduzindo a velocidade de germinação na concentração de $10^{-2} \mathrm{M}$, mas não afetando a porcentagem de germinação. Em tomate, o herbicida 

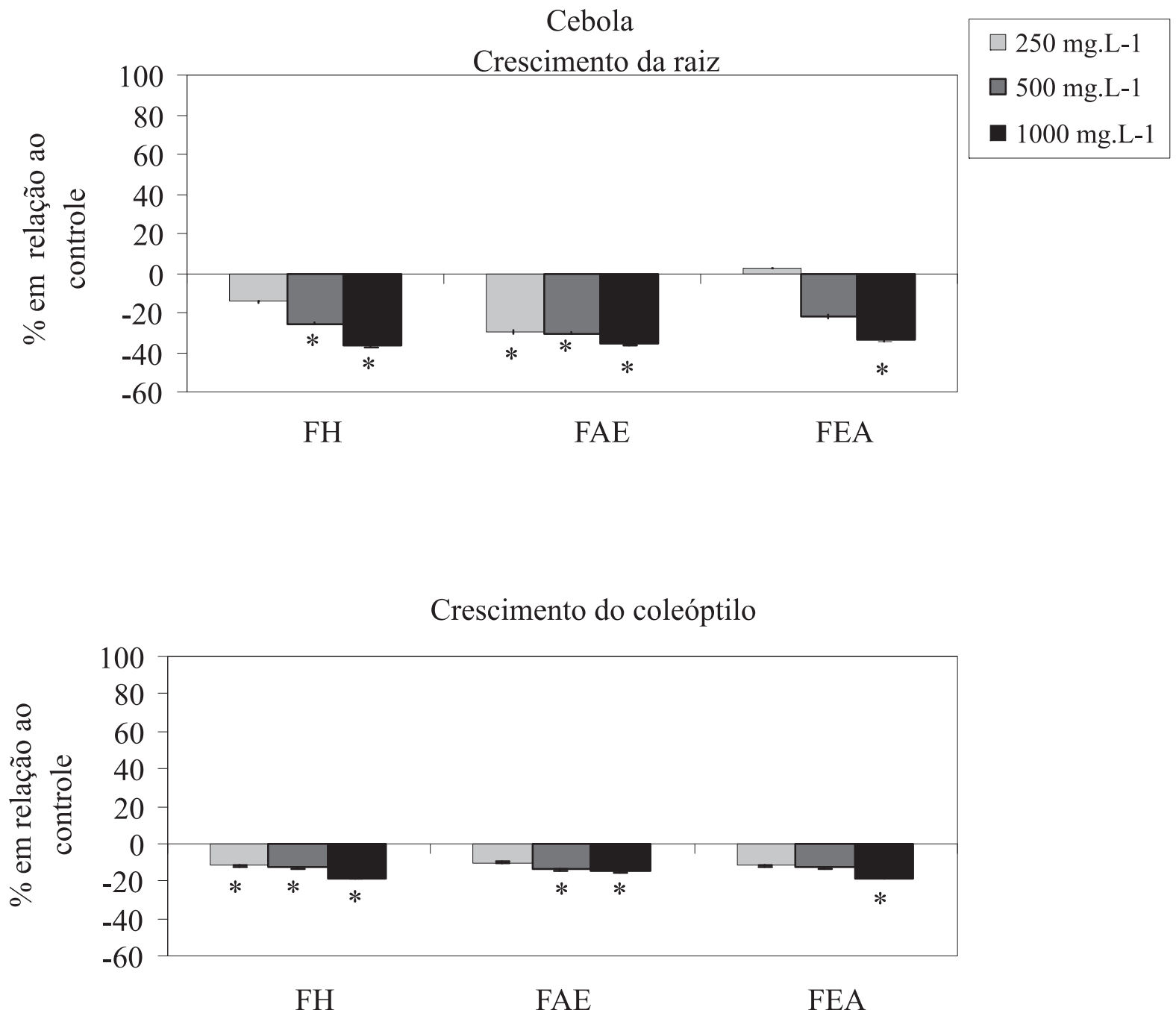

Figura 3. Efeito das frações hexânica (FH), acetato de etila (FAE) e etanol-água (FEA) da parte aérea de Senna occidentalis no crescimento médio da raiz e do coleóptilo de cebola. Dados expressos em percentual em relação ao controle. *A média do tratamento difere significativamente (p $<0,05)$ em comparação com a média do controle, pelo teste de Kruskal-Wallis (e Mann Whiteny U).

atrazina na concentração de $10^{-2} \mathrm{M}$ agiu de modo similar a $\mathrm{FH}$ e a FAE, reduzindo a velocidade de germinação das plântulas-alvo e a porcentagem de germinação ( \pm 7\%). Nas monocotiledôneas, o herbicida gesagard agiu de maneira similar a FEA em cebola e, também, a todas as frações em trigo, não influenciando na germinação das sementes. Esses resultados sugerem que as frações avaliadas apresentam compostos químicos que agem de modo similar aos herbicidas comerciais, afetando o processo germinativo tanto de eudicotiledôneas como de monocotiledôneas. Macias et al. (1999) isolaram substâncias de folhas de $H$. annuus que apresentavam efeito similar ao herbicida logran.

No crescimento radicial e da parte aérea das eudicotiledôneas, FH e FAE foram as que influenciaram de forma mais intensa o desenvolvimento das plântulas, enquanto nas monocotiledôneas todas as frações afetaram o crescimento (raiz e/ou coleóptilo), tendo sido verificado que os efeitos cau- sados pelas frações variaram dependendo da espécie-alvo e das concentrações utilizadas. Comparando-se o crescimento da raiz e da parte aérea (hipocótilo/coleóptilo), é observado que os efeitos fitotóxicos foram mais evidentes no crescimento da raiz do que na parte aérea. Isso pode ter ocorrido devido à absorção e, conseqüentemente, a concentração de fitotoxinas nos tecidos radiculares ter sido favorecida pelo contato físico da raiz com o papel filtro, o qual continha as frações. Tem sido reportado que a bioatividade das frações está condicionada à capacidade de absorção, translocação e mecanismo de ação de seus compostos potencialmente alelopáticos (Correia et al. 2005).

Assim, pode ser concluído que as frações em estudos interferem na germinação e no crescimento inicial das plântulas alvo, sendo verificado efeito alelopático mais evidente no IVG e crescimento radicial das plântulas do que na porcentagem final de sementes germinadas, fato também observado por Periotto et al. (2004). Por outro lado, nenhum 


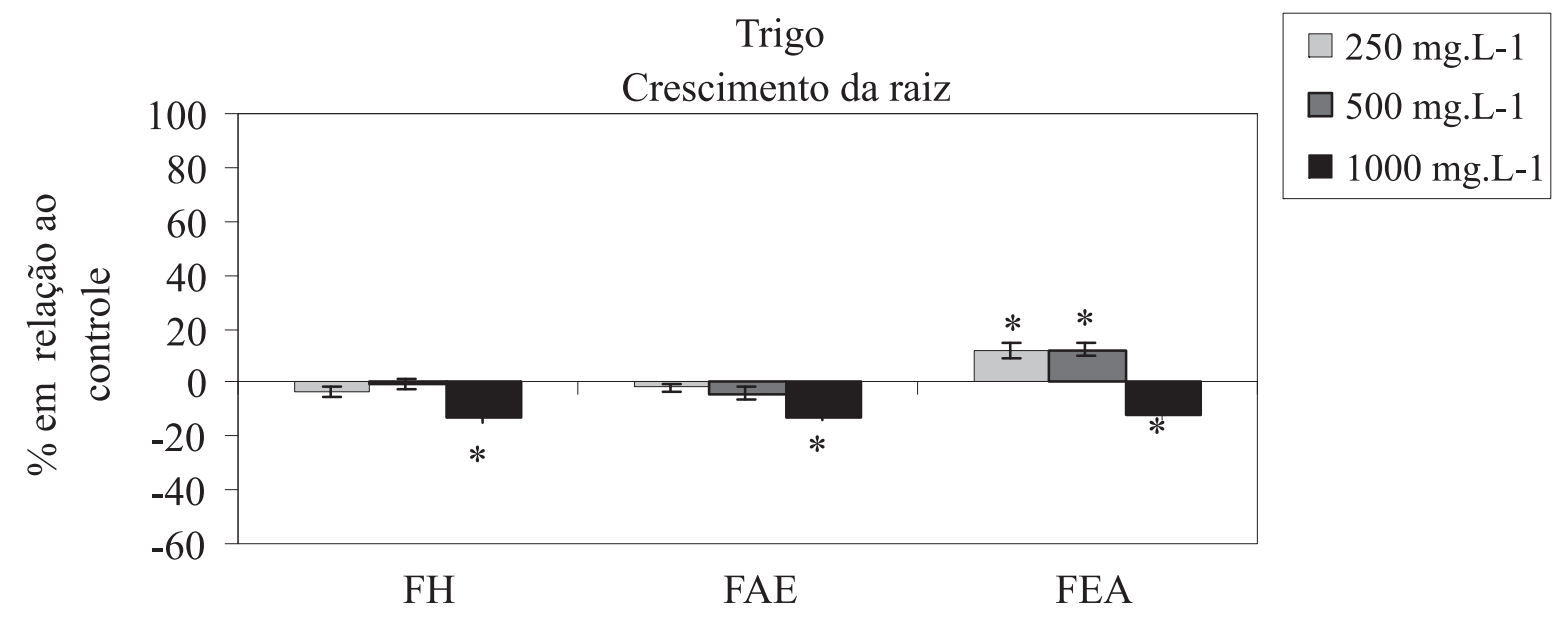

Crescimento do coleóptilo

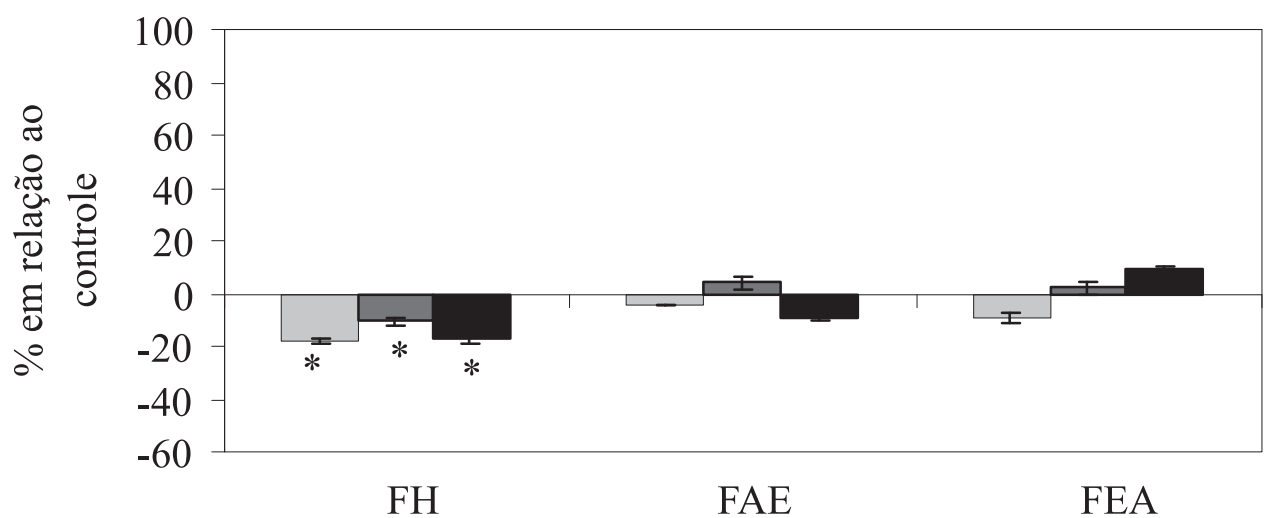

Figura 4. Efeito das frações hexânica (FH), acetato de etila (FAE) e etanol-água (FEA) da parte aérea de Senna occidentalis no crescimento médio da raiz e do coleóptilo de trigo. Dados expressos em percentual em relação ao controle. *A média do tratamento difere significativamente ( $\mathrm{p}<0,05)$ em comparação com a média do controle, pelo teste de Dunnet.

Tabela 3. Total* de fenóis e flavonóides presentes nas frações semipurificadas da parte aérea de S. occidentalis.

\begin{tabular}{lcc}
\hline & $\begin{array}{c}\text { Total de fenóis** } \\
(\mu \mathrm{g} \mathrm{EAG} \mathrm{mg} \mathrm{de} \mathrm{fração-1})\end{array}$ & $\begin{array}{c}\text { Total flavonóides } \\
(\mu \mathrm{g} \text { EQ mg de fração }\end{array}$ \\
\hline Fração hexânica & $54,050 \pm 0,012$ & $37,500 \pm 0,008$ \\
Fração acetato de etila & $101,860 \pm 0,037$ & $50,500 \pm 0,060$ \\
Fração etanol-água & $50,037 \pm 0,016$ & $7,180 \pm 0,016$ \\
\hline
\end{tabular}

* Média \pm desvio padrão.

**Expresso em equivalente de ácido gálico (EAG) por miligrama de fração.

\# Expresso em equivalente de quercetina (EQ) por miligrama de fração.

efeito significativo foi verificado na massa seca das plântulas, quando comparadas ao controle.

Nos testes de cromatografia em camada delgada, foi verificada a presença de terpenos na FH e de compostos fenólicos na FAE. Também foi detectada a presença de alcalóides na fração básica em acetato de etila. Em adição, na Tab. 3 estão mostrados os resultados obtidos nos testes realizados com as frações semipurificadas da parte aérea de S. occidentalis, referentes à determinação dos teores totais de fenóis e flavonóides, expressos como equivalentes de ácido gálico (EAG) e quercetina (EQ), respectivamente. Os conteúdos mais elevados de fenóis e flavonóides foram verificados na FAE, com valores de $101,860 \pm 0,037 \mu \mathrm{g}$ EAG mg ${ }^{-1}$ e 50,500 $\pm 0,060 \mu \mathrm{g}$ EQ 
$\mathrm{mg}^{-1}$, respectivamente. A maioria das espécies de Cassia e Senna que ocorrem no Brasil, tais como C. spectabilis, C. carnaval e C. excelsa, revelou a presença de alcalóides piperidínicos como constituintes majoritários, além de flavonas glicosiladas, ésteres alifáticos de cadeia longa, cromona glicosilada e polissacarídeos (Viegas Junior et at. 2006), corroborando com as classes de compostos detectados na FAE avaliada no presente estudo. A rigor, a literatura relata o isolamento de mais de 350 metabólitos secundários em espécies do gênero Senna, distribuídas em regiões tropicais e subtropicais de várias partes do mundo. Foi evidenciada a ocorrência de substâncias de várias classes de compostos, sendo antraquinonas e flavonóides os constituintes mais freqüentes na maioria das espécies relatadas na literatura (Morimoto et al. 1988; LuximonRamma et al. 2002; Kim et al. 2004).

Com o presente trabalho, pode ser concluído que a parte aérea de $S$. occidentalis contém substâncias químicas responsáveis pela interferência na germinação e crescimento inicial das espécies alvo, em estudo, de eudicotiledôneas e monocotiledôneas, podendo ser útil como herbicida natural em programas de manejo de plantas invasoras.

\section{Agradecimentos}

Ao Prof. Dr. Alan Sciamarelli, pela identificação botânica. À PROPP/ UFMS e FUNDECT/MS, pelo auxílio financeiro.

\section{Referências bibliográficas}

Araújo, A.S.F. \& Araújo, R.S. 2006. Sobrevivência e nodulação de Rhizobium tropici em sementes de feijão tratadas com fungicidas. Ciência Rural 36(3): 973-976.

Barnes, J.P.; Putnan, A.R.; Burke, B.A. \& Aasen, A.J. 1987. Isolation and characterization of allelochemicals in rye herbage. Phytochemistry 26(5): 1385-1390.

Brasil. Ministério da Agricultura e Reforma Agrária. 1992. Regras para a Análise de Sementes, SNDA/DNDU/CLU, Brasília.

Chauhan, D.; Chauhan, J.S.; Siddiqui, I.R. \& Singh, J. 2001. Two new anthraquinone glycosides from the leaves of Cassia occidentalis. Indian Journal of Chemistry. 40b: 860-863.

Correia, N.M.; Centurion, M.A.P.C. \& Alves, P.L.C.A. 2005. Influência de extratos aquosos sobre a germinação e o desenvolvimento de plântulas de soja. Ciência Rural 35(3): 498-503.

Dayan, F.E.; Romagni, J.G. \& Duke, S.O. 2000. Investigating the mode of action of natural phytotoxins. Journal of Chemical Ecology 26(9): 2079-2093.

Duke, S.O.; Dayan, F.E.; Rimando, A.M.; Schrader, K.K.; Oliva, G.A.A. \& Romagni, J.G. 2002. Invited paper: chemicals from nature for weed management. Weed Science 50: 138-151.

Duringan, J.C. \& Almeida, F.L.S. 1993. Noções sobre Alelopatia. Jaboticabal, FUNEP.

Einhellig, F.A. 2002. The physiology of allelochemical action: Clues and Views. Pp. 1-23. In: Reigosa, M. \& Pedrol, N. (eds.). Allelopathy from Molecules to Ecosystems. Vigo, Universidade de Vigo.

Ferreira, A.G. \& Borghetti, F. 2004. Interpretação de resultados de germinação. Pp. 209-222. In: Ferreira, A.G. \& Borghetti, F. (eds). Germinação do Básico ao Aplicado. Porto Alegre, Artmed.

Kim, Y.M.; Lee, C.H.; Kim, H.G. \& Lee, H.S. 2004. Anthraquinones isolated from Cassia tora (Leguminosae) seed show an antifungal property against phytopathogenic fungi. Journal of Agricultural and Food Chemistry 52: 6096-6100.

Labouriau, L.G. 1983. A Germinação das Sementes. Secretaria geral da organização dos Estados Americanos. Washington D.C., Estados Unidos.

Lin, J.Y. \& Tang, C.Y. 2007. Determination of total phenolic and flavonoid contents in selected fruits and vegetables, as well as their stimulatory effects on mouse splenocyte proliferation. Food Chemistry 101: 140-147.

Lorenzi, H. 2000. Plantas Daninhas do Brasil: terrestres, aquáticas, parasitas e tóxicas. 3 ed. Nova Odessa, Plantarum,

Luximon-Ramma, A.; Baiorun, T.; Soobrattee, M.A. \& Aruoma, O.I. 2002. Antioxidant activities of phenolic, proanthocyanidin, and flavonoid components in extracts of Cassia fistula. Journal of Agricultural and Food Chemistry 50: 5042-5047.

Macias, F.A.; Galindo, J.C.G.; Molinillo, J.M.G.; Castellano, D.; Velasco, R.F. \& Chinchila, D. 1999. Developing new herbicide models from allelochemicals. Pesticide Science 55: 662-665.

Macias, F.A.; Castellano, D. \& Molinillo, J.M.G. 2000a. Search for a standard phytotoxic bioassay for allelochemicals. Selection of standard target species. Journal of Agricultural and Food Chemistry 48 (6): 2512-2521.

Macias, F.A.; Gallindo, J.C.G. \& Molinillo, J.M.G. 2000b. Plant biocommunicators: application of allelopathic studies. In: 2000 Years of Natural Products Research Past, Present and Future, Ed Teus J.C. Luijendijk, Phytoconsult.

Macias, F.A.; Fernandez, A.; Varela, R.M.; Molinillo, J.M.G.; Torres, A. \& Alves, P.L.C.A. 2006. Sesquiterpene lactones as allelochemicals. Journal of Natural Products 69(5): 795-800.

Maraschin-Silva, F. \& Aquila, M.E.A. 2006. Potencial alelopático de espécies nativas na germinação e crescimento inicial de Lactuca sativa L. (Asteraceae). Acta Botanica Brasilica 20(1): 61-69.

Meda, A.; Lamien, C.E. \& Beecher, G.R. 2005. Determination of the total phenolic, flavonoid and praline contensts in Burkina fasan honey, as well as their radical scavenging activity. Food Chemistry 91: 571-577.

Morel, A.F.; Maldaner, G.; Ilha, V.; Missau, F.; Silva, U.F.; Dacol, I.I. 2005. Cyclopeptide alkaloides from Scutia buxifolia Reiss and their antimicrobial activity. Phytochemistry 66: 2571-2576.

Morimoto, S.; Nonaka, G.I.; Chen, R.F. \& Nishioka, I. 1988. Tannins and related compounds. LXI. Isolation and structures of novel bi- and triflavonoids from the leaves of Cassia fistula L. Chemical Pharmaceutical Bulletin 36(1): 39-47.

Peres, M.T.L.P.; Silva, L.B.; Faccenda, O. \& Hess, S.C. 2004. Potencial alelopático de espécies de Pteridaceae (Pteridophyta). Acta Botanica Brasilica 18(4): 723-730.

Periotto, F.; Perez, S.C.J.G.A. \& Lima, M.I.S. 2004. Efeito alelopático de Andira humilis Mart. Ex Benth na germinação e no crescimento de Lactuca sativa L. e Raphanus sativus L. Acta Botanica Brasilica 18(3): 425-430.

Rice, L. 1984. Allelopathy. Londren, Academic Press.

Rodrigues, R.S.; Flores, A.S.; Miotto, S.T.S. \& Baptista, L.R.M. 2005. O gênero Senna (Leguminosae, Caesalpinioideae) no Rio Grande do Sul, Brasil. Acta Botanica Brasilica 19(1): 1-16.

Soares, G.L.G.; Scalon, V.R.; Pereira, T.O. \& Vieira, D.A. 2002. Potencial alelopático do extrato aquoso de folhas de algumas leguminosas arbóreas brasileiras. Floresta e Ambiente 9(1): 119-126.

Viegas Junior, C.; Rezende, A.; Silva, D.H.S.; Castro-Gambôa, I.; Bolzani, V.S.; Barreiro, E.J.; Miranda, A.L.P.; Alexandre-Moreira, M.S. \& Young, M.C.M. 2006. Aspectos químicos, biológicos e etnofarmacológicos do gênero Cassia. Química Nova. 29(6): 1-8.

Wader, G.R. \& Kudav, N.A. 1987. Chemical investigation of Cassia occidentalis Linn. with special reference to isolation of xanthones fron Cassias species. Indian Journal of Chemistry. 26b: 703. 